\title{
Analysis on Value added Equilibrium of Enterprise Marketing Networks
}

\author{
,Xiao Hong Qin ${ }^{1, a^{*}}$, Yong Hong Du ${ }^{1, b}$ \\ School of Economics and Business xijing University xi'an 710023,China \\ aqinxiaohong12@sohu.com, b80477659@qq.com
}

Keywords: Enterprise marketing networks; Marketing channels; Value added; Game theory Value added Equilibrium

\begin{abstract}
Enterprise marketing networks has evolved into complex marketing networks from chain of marketing channel. However, current enterprise marketing networks has studied more limited to game decision-making of the single channel between upstream and downstream members. To considering the marketing channels of enterprise marketing networks has complex competitive relationship, the article has build the enterprise network marketing value equilibrium model, and has studied the different marketing channels of static game decision-making and under asymmetric information and cost game decision making. The article has from an example to explain the model of economic significance.
\end{abstract}

\section{Introduction}

The investigative of enterprise marketing networks is limited a single marketing channels upstream and downstream members decision-making, which studies can be seen as a single marketing channel upstream and downstream enterprises channels Game-making [1,2,3,4,5].The existing examination about enterprise marketing networks has no studied decision-making of across the single marketing channel. As market competition intensifies, the single marketing channel interrelated and intertwined to form a complex marketing network in order to meet the needs of the end customer and get to maximize their own interests. There are variety of competing relationship in enterprise marketing networks, and game theory as an analysis tools are widely to use [6]. Competition and cooperation relationship of enterprise marketing networks are around value creation and value-added. For most enterprise marketing networks, value-added and network surplus is strong positive relationship.The revenue surplus is total profits for the marketing networks all the links shared, which from the difference between the sales revenue and the total cost of enterprise marketing networks sale of the marketing network marketing networks.

\section{The static game decision-making between different marketing channels}

Assumptions enterprise marketing networks structure remains unchanged.Assuming enterprise marketing networks has $M C_{A}$ and $M C_{B}$ marketing channels which core members respectively is $C M_{A}$ and $C M_{B}$.The value-added of individual marketing channels is $\Delta V$, then:

$$
\Delta V=P-\sum C
$$

Which $P$ denote the price of product reaches the end users or consumers. $\sum C$ denote total cost of marketing channels, which including the manufacturer's production $\operatorname{cost} C_{p}$ and producers and middlemen (wholesalers, retailers, etc.) production sales cost $C_{S}$, warehousing costs $C_{H}$,transportation costs $C_{T}$, and other costs $C_{O}$, then:

$$
\sum C=C_{p}+C_{s}+C_{h}+C_{t}+C_{o}
$$


Assume that two single marketing channel $M C_{A}$ and $M C_{B}$ in the process of market competition, which pursuit of their own value-added to maximize, the objective function is:

$$
M \operatorname{ax} \pi_{i}\left(Q_{i}, Q\right)=M \operatorname{ax}\left\{(a-b) Q-\left[\left(C_{p}\right)_{i}+\left(C_{s}\right)_{i}+\left(C_{h}\right)_{i}+\left(C_{t}\right)_{i}+\left(C_{o}\right)_{i}\right] Q_{i}\right\}
$$

Which $i=A, B, Q=\sum Q_{A}+Q_{B}, Q_{A}$ and $Q_{B}$ is respectively product sales of marketing channels $M C_{A}$ and $M C_{B}$, and $a, b$ is constant. $a$ can understanding for the highest price of the product in the market. $b$ can understanding additional sale a unit of product due to price declines (it is impact of sales quantity for sales pricemarginal ).

Assumption $M C_{A}$ costs is $\sum C_{A}$ and $M C_{B}$ cost is $\sum C_{n}$, whch are public knowledge. Two single marketing channel ${ }_{M C}$ and ${ }_{m C}$, all know own cost and other cost .For single marketing channel ${ }_{m C}$, we seek product sell $Q_{A}^{*}$ when achieve their own value-added maximize. Which is equal to seek the first order derivative and second derivative of the formula (3), and satisfies:

$$
\begin{aligned}
& \left\{\left[a-b\left(Q_{A}+Q_{B}\right)-\sum C_{A}\right] \times Q_{A}\right\} Q_{A}=0 \\
& \left\{\left[a-b\left(Q_{A}+Q_{B}\right)-\sum C_{A}\right] \times Q_{A}\right\}^{\prime \prime} Q_{A}<0
\end{aligned}
$$

Because the formula (5) is always established when $\pi_{A}$ is positive. Can be obtained from the formula (4):

$$
Q_{A}^{*}=\left(a-b Q_{B}-\sum C_{A}\right) /(2 b)
$$

Similarly can be obtained a single marketing channel $M C_{B}$ its product sales quantity when it achieve their own added value maximization:

$$
Q_{B}^{*}=\left(a-b Q_{A}-\sum C_{B}\right) /(2 b)
$$

Formula (6) and (7) simultaneous, respectively to obtain the two marketing channels $M C_{A}$ and $M C_{B}$ product sales quantity when maximized their own value-added as follows:

$$
\begin{aligned}
& Q_{A}^{*}=\left(a+\sum C_{B}-2 \sum C_{A}\right) /(3 b) \\
& Q_{B}^{*}=\left(a+\sum C_{A}-2 \sum C_{B}\right) /(3 b)
\end{aligned}
$$

$M C_{A}$ and $M C_{B}$ product sales price when realize the maximized value added as follows:

$$
Q_{A}^{*}=\left(a+\sum C_{B}-2 \sum C_{A}\right) /(3 b)
$$

$M C_{A}$ and $M C_{B}$ respect profits when achieve added value maximized as follow:

$$
\begin{aligned}
& \pi_{A}^{*}\left(Q_{A}^{*}, Q^{*}\right)=P^{*} Q_{A}^{*}-\sum C_{A} Q_{A}^{*} \\
& \pi_{B}^{*}\left(Q_{B}^{*}, Q^{*}\right)=P^{*} Q_{B}^{*}-\sum C_{B} Q_{B}^{*}
\end{aligned}
$$

From the formula (8) and (9) we can see that the best product sales of single marketing channel is not only associated with its own costs, but also relate to the cost of other marketing channels (competitors). The single marketing channel greater value-added is that has highest price of in the market and lower own costs and competitors (other marketing channels) higher cost. For example, the member of enterprise marketing networks strengthen information sharing, and implement dynamic order to reduce cost of marketing channels[7,8] .

\section{Game decision-making of different marketing channels under asymmetric information}

Assuming $M C_{A}$ form earlier than $M C_{B} . M C_{A}$ cost of $\sum C_{A}$ is public knowledge. $M C_{B}$ cost of $\sum C_{B}$ is private knowledge. $M C_{A}$ only know that the cost of $M C_{B}$ may be $p$ and $(1-p)$ probability 
of high-cost $\sum C_{B H}$ or low-cost $\sum C_{B L}$. But $M C_{B}$ know that their own costs is $\sum C_{B H}$ or $\sum C_{B L}$. For single marketing channel $M C_{A}, \sum C_{B}$ is random variables, and expectation is $E\left(C_{B}\right)=P \sum C_{B H}+(1-P) \sum C_{B L}$.

In the case of cost information asymmetry, due to $M C_{A}$ cost $\sum C_{A}$ is public knowledge. The $M C_{B}$ objective function:

$$
\operatorname{Max}_{B}\left(Q_{B}, Q\right)=\operatorname{Max}\left[a-b\left(Q_{A}+Q_{B}\right)-\sum C_{B}\right] Q_{B}
$$

To seek the formula (13) for $Q_{B}$ the first derivative and the second derivatives, and to let the first derivative equal zero, and the second derivative is less than 0 , then:

$$
\begin{aligned}
& \left\{\left[a-b\left(Q_{A}+Q_{B}\right)-\sum C_{B}\right] Q_{B}\right\}^{\prime} Q_{B}=0 \\
& \left\{\left[a-b\left(Q_{A}+Q_{B}\right)-\sum C_{B}\right] Q_{B}\right\}^{\prime \prime} Q_{B}<0
\end{aligned}
$$

Because the formula (15) is always true in the case $b>0$, so from the formula (14) we available $M C_{B}$ product sales quantity when add value maximum:

$$
Q_{B}^{*}=\left(a-b Q_{A}^{*}-\sum C_{B}\right) /(2 b)
$$

Because $M C_{A}$ only know probability of $M C_{B}$ take the high cost $\sum C_{B H}$ or low cost $\sum C_{B L}$, therefore, the $M C_{A}$ objective function is:

$$
\operatorname{Max}_{A}\left(Q_{A}, Q\right)=\operatorname{Max}\left\{\left[\left(a-b\left(Q_{A}+Q_{B H}\right)-\sum C_{A}\right] Q_{A} P+Q_{A}(1-P)\left[\left(a-b\left(Q_{A}+Q_{B L}\right)-\sum C_{A}\right]\right\}\right.\right.
$$

$Q_{B H}$ and $Q_{B L}$ respectively is product sales of $M C_{B}$ in the cost $\sum C_{B H}$ and $\sum C_{B L}$; to solute sales of $M C_{A}$ with maximum value added:

$$
Q_{A}^{*}=\left(a-\sum C_{A}-b\left[p Q_{B H}+(1-p) Q_{B L}\right]\right)
$$

$M C_{A}$ and $M C_{B}$ sales respectively as follow, in the case of game behavior and achieve value-added maximum:

$$
\begin{gathered}
Q_{A}^{*}=\left(a-2 \sum C_{A}+\left[p \sum C_{B H}+(1-p) C_{B L}\right]\right) /(3 b) \\
Q_{B}^{*}=\left(a+\sum C_{A}-2 \sum C_{B}\right) /(3 b)
\end{gathered}
$$

Among $\sum C_{B} \in\left\{\sum C_{B H}, \sum C_{B L}\right\}, M C_{A}$ and $M C_{B}$ game decision-making on product sales achieve balanced, $M C_{A}$ and $M C_{B}$ the total product sales as follow:

In this case the price of the product :

$$
Q^{*}=Q_{A}^{*}+Q_{B}^{*}
$$

$$
P^{*}=a-b Q^{*}
$$

the corresponding $M C_{A}$ and $M C_{B}$ equilibrium value added as follows:

$$
\begin{gathered}
\pi_{A}^{*}\left(Q_{A}^{*}, Q^{*}\right)=P^{*} Q_{A}^{*}-\sum C_{A} Q_{A}^{*} \\
\pi_{B}^{*}\left(Q_{B}^{*}, Q^{*}\right)=P^{*} Q_{B}^{*}-C_{B} Q_{B}^{*}
\end{gathered}
$$

Among, $\sum C_{B} \in\left\{\sum C_{B H}, \sum C_{B L}\right\}$.

These results suggest that in the case of asymmetric information costs optimal product sales decisions and optimal value-added are consistent with complete information costs.Marketing channels $M C_{A}$ optimal product sales decisions and optimal value-added with incomplete information different cost information disclosure. Which not only by impact of cost factors, and also depends on forecast competitors cost accuracy. 


\section{Numerical example}

Assuming marketing channels $M C_{A}$ and $M C_{B}$ of enterprise marketing networks are collaborative monopoly a regional marke, the cost $M C_{A}$ and $M C_{B}$ respectively is:

$\sum C_{A}=\left(C_{p}\right)_{A}+\left(C_{s}\right)_{A}+\left(C_{h}\right)_{A}+\left(C_{t}\right)_{A}+\left(C_{o}\right)_{A}=35+20+10+18+7=90$

$\sum C_{B H}=\left(C_{p}\right)_{B H}+\left(C_{s}\right)_{B H}+\left(C_{h}\right)_{B H}+\left(C_{t}\right)_{B H}+\left(C_{o}\right)_{B H}=35+25+12+18+10=100$

$\sum C_{B L}=\left(C_{p}\right)_{B L}+\left(C_{s}\right)_{B L}+\left(C_{h}\right)_{B L}+\left(C_{t}\right)_{B L}+\left(C_{o}\right)_{B L}=35+18+8+15+9=85$

The maximum sales price of product on the market is $a=150$.Each a unit of product additional sale to drop price is $b=0.1$. The probability of marketing channels $M C_{B}$ with high cost for product marketing is uncertainty.We comparative analysis $p=0.2$ and $p=0.6$ both cases. Table 1 and Table 2 respectively showed that $M C_{A}$ and $M C_{B}$ Optimal product sales strategy and largest value-added when $M C_{B}$ with $C_{B H}$ and $C_{B L}$ for product marketing.

Table 1 three situations of $M C_{B}$ with $C_{B H}$ for product marketing

\begin{tabular}{|c|c|c|c|c|}
\hline & \multirow{2}{*}{$\begin{array}{l}\text { (1) } \sum C_{B} \text { is } \sum C_{B H} \\
\text { and } M C_{A} \text { forecast } \\
C_{B H}\end{array}$} & \multirow{2}{*}{$\begin{array}{l}\text { (2) } \sum C_{B} \text { is } \sum C_{B H} \\
\text { and } M C_{A} \text { forecast } \\
C_{B L}\end{array}$} & \multicolumn{2}{|c|}{$\begin{array}{l}\text { (3) } \sum C_{B} \text { is } \sum C_{B H} \text { and } M C_{A} \\
\text { use } E\left(\sum C_{B}\right) \text { to calculate }\end{array}$} \\
\hline & & & $p=0.2$ & $p=0.6$ \\
\hline$P^{*}$ & 113 & 118 & 117 & 115 \\
\hline$Q_{A}^{*}$ & 233 & 183 & 193 & 213 \\
\hline \multirow[t]{2}{*}{$Q_{B}^{*}$} & 133 & 133 & 133 & 133 \\
\hline & & $\begin{array}{l}\text { Per unit of product } \\
\text { selling prices rise } \\
5 \text { yuan }\end{array}$ & $\begin{array}{l}\text { Per unit of } \\
\text { product selling } \\
\text { prices rise } 4\end{array}$ & $\begin{array}{l}\text { Per unit of product } \\
\text { selling prices rise } \\
2 \text { yuan }\end{array}$ \\
\hline$\pi_{A}^{*}$ & 5359 & 5124 & 5211 & 5325 \\
\hline$\pi_{B}^{*}$ & 1729 & 2394 & 2261 & 1995 \\
\hline
\end{tabular}

From Table 1 we can see three cases if $M C_{B}$ cost is $C_{B H}$ : The $M C_{A}$ can get the highest value-added when the $M C_{A}$ predict correct; When $M C_{A}$ decision-making is low cost of $M C_{B}, M C_{A}$ actual sales of products than optimal sales of products small lead to raise of price in the market. In this case, the $M C_{A}$ get smallest value-added, while the $M C_{B}$ get highest value-added; When $M C_{A}$ to make decision in accordance with expectation value the cost of $M C_{B}, M C_{A}$ value-added lesser than forecast correct decisions, but value-added significantly better than prediction errors. While $M C_{B}$ still benefit from mis-prediction of $M C_{A}$, and $M C_{B}$ enjoy higher market price and value-added .

Table 2 three situations of $M C_{B}$ with $C_{B L}$ for product marketing

\begin{tabular}{|c|c|c|c|c|}
\hline & \multirow{2}{*}{$\begin{array}{l}\text { (1) } \sum C_{B} \text { is } \sum C_{B L} \\
\text { and } M C_{A} \text { forecast } \\
C_{B L}\end{array}$} & \multirow{2}{*}{$\begin{array}{l}\text { (2) } \sum C_{B} \text { is } \sum C_{B L} \\
\text { and } M C_{A} \text { forecast } \\
C_{B H}\end{array}$} & \multicolumn{2}{|c|}{$\begin{array}{l}\text { (3) } \sum C_{B} \text { is } \sum C_{B H} \text { and } \\
M C_{A} \text { use } E\left(\sum C_{B}\right) \text { to calculate }\end{array}$} \\
\hline & & & $p=0.2$ & $p=0.6$ \\
\hline$P^{*}$ & 108 & 103 & 107 & 105 \\
\hline$Q_{A}^{*}$ & 183 & 233 & 193 & 213 \\
\hline \multirow[t]{2}{*}{$Q_{B}^{*}$} & 233 & 233 & 233 & 233 \\
\hline & & $\begin{array}{l}\text { Per unit of product } \\
\text { selling prices rise } \\
5 \text { yuan }\end{array}$ & $\begin{array}{l}\text { Per unit of product } \\
\text { selling prices rise } \\
6 \text { yuan }\end{array}$ & $\begin{array}{l}\text { Per unit of } \\
\text { product } \\
\text { selling prices } \\
\text { rise } 8 \text { yuan }\end{array}$ \\
\hline$\pi_{A}^{*}$ & 3294 & 3029 & 3281 & 3195 \\
\hline$\pi_{B}^{*}$ & 5359 & 4194 & 1631 & 1165 \\
\hline
\end{tabular}


From Table 2 we can see three cases: $M C_{A}$ can get highest value-added when $M C_{A}$ prediction correct in the case of $M C_{B}$ cost is $\sum C_{B L}$; When $M C_{A}$ accordance with high cost of $M C_{B}$ decision, $M C_{A}$ actual sales more than optimal sales to lead lower prices of products in the market, $M C_{A}$ get lowest value-added but value-added of $M C_{B}$ also suffer losses due to price reduction of product in market; When $M C_{A}$ accord with expectation cost of $M C_{B}$ to make decision, then $M C_{A}$ value-added lesser than forecast correct, but significantly better than prediction errors. While $M C_{B}$ still suffer mis-prediction of $M C_{A}$ and suffer lower market price and value-added.

\section{Conclusion}

If have incomplete cost information marketing channel is not using the expected value prediction of the other costs, only in the accurately predict each other's cost, to obtain the highest value; otherwise, not only will suffer due to inaccurate prediction of low value, and make the other side enjoy market price and relatively high added value. When the full cost information marketing channels the cost is lower than the other side, hope the other party can understand their cost information, this can be avoided because of the other prediction errors and the decision error caused by market prices, and avoid the loss of value added value.

\section{References}

[1] Yunlong Gao. Enterprise marketing network design and management [] Beijing: Social Sciences Academic Press,2006.1-4.

[2]Xiaohong Guangqiu Huang.Robustness Analysis of enterprise marketing network based on complex network theory[J]. Business Research, 2010,23 (12) :43-38.

[3] Anna Nagurney, June Dong, Ding Zhang. A Supply Chain Network Equilibrium Model[J].Transportation Research,2002,38(5):281-304.

[4] June Dong, Ding Zhang, Hong Yan, et al. Supply Chain Networks: Decision-Making Under Uncertainty [J]. Annals of Operations Research,2005,135(1):155-180.

[5] Lalonde B J. Supply Chain Management: Myth or Reality [J]. Supply Chain Management Review,2006, 12(1):6-7.

[6] Zhang Xinrui, Wang Hengshan. The complex supply chain network structure model of[J]. industry technology and economy, 2008 (2): 70-81.

[7] Zhang Xinrui, Wang Hengshan. Supply chain network value-added game decision making research on [J]. Business Economics and management, 2009 (7): 70-81

[8] Zhang Tiezhu, Hu Yunquan, et al. The multi-layer planning of decentralized supply chain model of [J]. Natural Science Journal of Heilongjiang University, 2006,23 (3): 302-306 